\begin{tabular}{|c|c|c|}
\hline $\begin{array}{l}\text { OPEN ACCESS } \\
\text { Vol. } 3 \text { No. 1: 1-9 } \\
\text { Tahun 2019 } \\
\text { Artikel penelitian 圆 }\end{array}$ & $\begin{array}{c}\text { Durreal Altuatililestari } \\
\text { E-ISSN: 2598-8204 } \\
\text { https://ojs.umrah.ac.id/index.php/akuatiklestari } \\
\text { Dol : https://doi.org/10.31629/akuatiklestari.v3i1.921 }\end{array}$ & $\begin{array}{l}Q= \\
\vdots \\
\vdots= \\
0=\end{array}$ \\
\hline
\end{tabular}

\title{
Analisis Kesesuaian Kawasan Wisata Pantai di Pulau Bungin Kecamatan Tambelan Kabupaten Bintan
}

\author{
Suitability Analysis of Coastal Tourism Areas on Bungin Island, Tambelan District, Bintan \\ Regency
}

\section{Raplianto $^{\circledR}$, Febrianti Lestari' ${ }^{1}$, Susiana ${ }^{1}$}

${ }^{1}$ Manajemen Sumberdaya Perairan, Fakultas Ilmu Kelautan dan Perikanan, Universitas Maritim Raja Ali Haji, Tanjungpinang, Indonesia 29111

\section{$\square$ Info Artikel:}

Diterima: 24 Januari 2019

Revisi: 02 Mei 2019

Disetujui: 10 Oktober 2019

Dipublikasi: 30 November 2019

\section{[Deyword:}

Kesesuaian Kawasan, Wisata Pantai, Pulau Bungin, Tambelan, Bintan

\begin{abstract}
ABSTRAK. Tujuan penelitian ini adalah untuk mengetahui potensi ekologis, tingkat kesesuaian kawasan wisata pantai dan daya dukung kawasan. Penelitian ini dilakukan dengan metode deskriptif kuantitatif. Hasil penelitian ini menunjukkan potensi ekologis kawasan pantai Pulau Bungin sesuai untuk dijadikan sebagai kawasan wisata pantai. Namun, sarana dan prasarana dan ketersediaan air tawar di Pulau Bungin tidak memadai. Tingkat kesesuaian kawasan wisata pantai di Pulau Bungin berdasarkan potensi ekologis memiliki nilai indeks kesesuaian wisata pada stasiun I dan II yaitu $81,58 \%$ dan 81,58 terkategori sangat sesuai (S1). Daya dukung kawasan pantai Pulau Bungin untuk aktivitas wisata pantai pada stasiun I dan II adalah 112 dan 138 jiwa dengan pemanfaatan luas area $50 \mathrm{~m}^{2} /$ orang untuk waktu kunjungan selama 3 jam/orang/hari. Berdasarkan kajian potensi ekologis, Pulau Bungin berpotensi untuk dijadikan kawasan wisata pantai.
\end{abstract}

ABSTRACT. The purpose of this study is to determine the ecological potential, the suitability level of the coastal tourism area, and the carrying capacity of the region. This research was conducted by the quantitative descriptive method. The results of this study indicate the ecological potential of the Bungin Island coastal area which is suitable to be used as a coastal tourism area. However, facilities and infrastructure as well as the availability of freshwater on Bungin Island are inadequate. The suitability level of the coastal tourism area on Bungin Island based on ecological potential has a value of tourism suitability index at stations I and II, namely $81.58 \%$ and 81.58 which are categorized very appropriately (S1). The carrying capacity of the coastal area of Bungin Island for beach tourism activities at stations I and II is 112 and 138 people with an area of $50 \mathrm{~m}^{2} /$ person for a visit time of 3 hours/person/day. Based on the study of ecological potential, Bungin Island has the potential to become a coastal tourism area.

How to cite this article:

Raplianto, Febrianti, L.., \& Susiana. (2019). Analisis Kesesuaian Kawasan Wisata Pantai di Pulau Bungin Kecamatan Tambelan Kabupaten Bintan. Jurnal Akuatiklestari, 3(1): 1-9. https://doi.org/10.31629/akuatiklestari.v3i1.921

\section{PENDAHULUAN}

Provinsi Kepulauan Riau merupakan salah satu provinsi di Indonesia yang memiliki luas laut lebih luas dari pada daratan yaitu 96\% lautan dan 4\% daratan, sehingga Kepulauan Riau memiliki potensi sumberdaya alam yang cukup untuk meningkatkan kehidupan dan kesejahteraan masyarakat khususnya masyarakat pesisir (BPS Kepulauan Riau, 2015). Provinsi Kepulauan Riau merupakan Provinsi ke-32 yang terbentuk berdasarkan Undang-Undang Nomor 25 Tahun 2002, Provinsi Kepulauan Riau memiliki luas wilayah sebesar 417.012,97 km² (BPS Kepulauan Riau, 2014).

Kawasan perairan yang memiliki potensi wisata bahari khususnya di wisata Pantai berada di Pulau Bungin Kecamatan Tambelan. Pulau Bungin adalah pulau yang berada di Kecamatan Tambelan yang masuk bagian dari Desa Batu Lepuk. Pulau Bungin merupakan salah satu pulau yang belum dihuni di Kecamatan Tambelan (Karnanda et al., 2019). Hal ini memungkinkan dilakukannya kegiatan wisata pantai yang masih alami di Pulau Bungin, karena belum adanya aktifitas masyarakat seperti pemukiman dan pariwisata yang akan mempengaruhi perairan dan kehidupan biota perairan. Salah satu ekosistem yang akan berdampak jika adanya aktivitas wisata yaitu pemandangan yang tidak enak karena sampah (Saputra et al., 2018). 
Pulau Bungin merupakan pulau yang belum dihuni di Kecamatan Tambelan, minim pembangunan sarana dan prasarana, lemahnya sistem pengelolaan. Untuk itu perlu adanya penelitian dalam bidang wisata khususnya dalam kesesuaian wisata pantai. dengan demikian perlu dilakukanya penelitian mengenai potensi sumberdaya perairan baik vegetasi pantai, pengelolaan aksesibilitas dan sarana prasarana yang ada di Pulau Bungin serta daya dukung Pulau Bungin khususnya tingkat kesesuaian wisata pantai. Maka, saat ini kebutuhan akan data dan informasi tentang potensi ekologi, potensi sosial dan kesesuaian kawasan wisata pantai serta daya dukung kawasan di Pulau Bungin penting untuk dimiliki dalam penetapan suatu kawasan pantai menjadi tujuan wisata pantai dan pengembangan wisata pantai pada waktu mendatang.

\section{METODE PENELITIAN}

\subsection{Waktu dan Tempat}

Penelitian ini dilaksanakan pada bulan Maret 2018 - Januari 2019 di Pulau Bungin, Kecamatan Tambelan Kabupaten Bintan, Provinsi Kepulauan Riau, Adapun wilayah penelitian dan titik koordinat stasiun penelitian dapat dilihat pada Gambar 1.

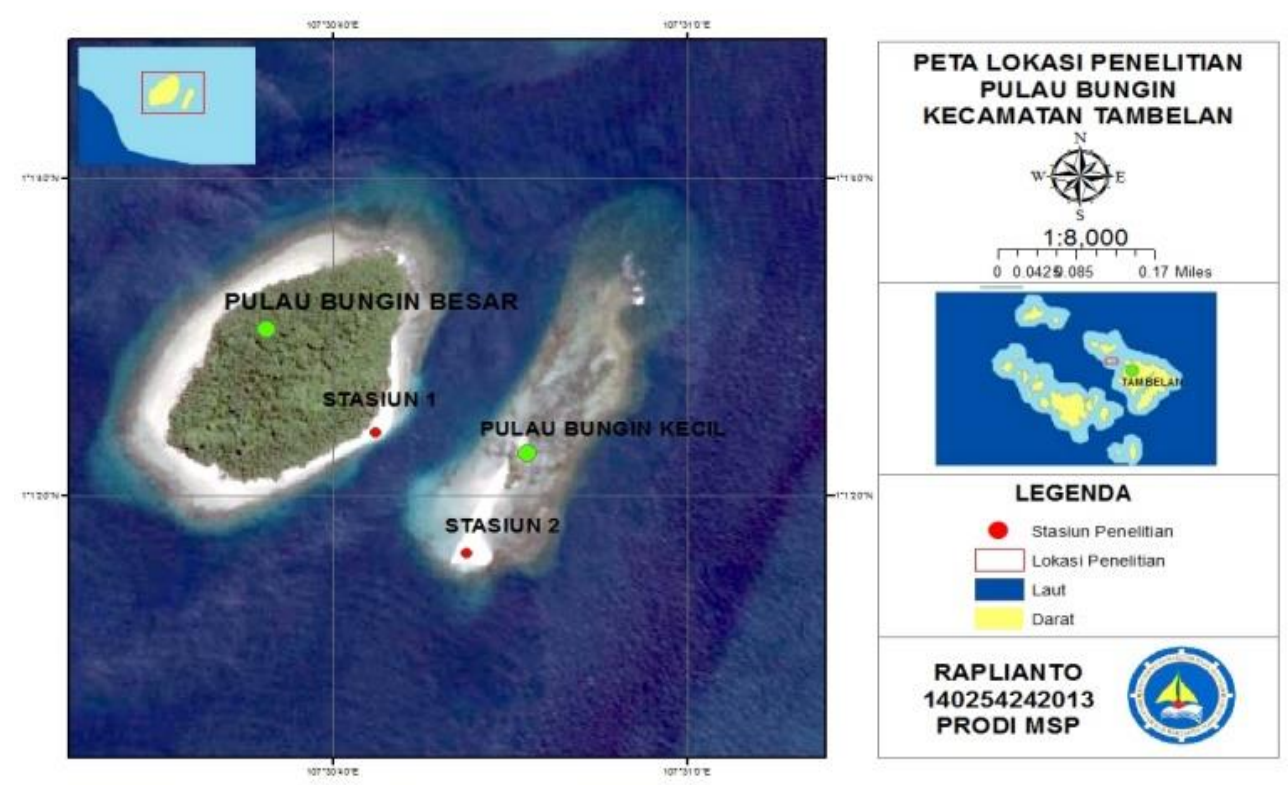

Gambar 1. Peta Lokasi Penelitian di Pulau Bungin, Kecamatan Tambelan

\subsection{Alat dan Bahan}

Alat-alat yang digunakan dalam penelitian ini antara lain alat tulis untuk mencatat hasil pengamatan in situ, tongkat skala untuk mengukur kedalaman perairan, kamera sebagai dokumentasi, roll meter untuk mengukur lebar pantai, tali dan botol untuk mengukur kecepatan arus, GPS (global positioning system) untuk menentukan titik koordinat, secchi disk untuk mengukur kecerahan, laptop sebagai pengolah data, kuisioner lembar wawancara, literatur lainnya sebagai data sekunder, waterpass untuk mengukur kemiringan pantai, sieve net sebagai penentuan material dasar perairan, oven untuk mengeringkan substrat, plastik sampel sebagai wadah substrat dan vegetasi, alumunium foil sebagai wadah mengeringkan substrat, timbangan analitik untuk menimbang sampel substrat, cawan petri sebagai wadah menimbang sampel susbtrat, sikat bulu untuk membersihkan sieve net, dan stopwatch untuk menghitung kecepatan arus.

Bahan-bahan yang digunakan dalam penelitian meliputi bahan yang menjadi objek penelitian di lapangan dan bahan yang digunakan dalam analisis laboratorium. Bahan yang digunakan dalam penelitian ini yaitu, substrat sebagai analisis fraksi substrat, vegetasi untuk identifikasi vegetasi penutupan lahan pantai dan alumunium foil untuk mengeringkan substart.

\subsection{Prosedur Penelitian}

Penelitian ini, menggunakan teknik purposive sampling untuk penentuan stasiun. Teknik purposive sampling adalah teknik pengambilan sampel sumber data dengan melihat pengunjung yang sering melakukan aktivitas di pantai tersebut serta keberadaan pasir putih (Safina et al., 2014). Titik koordinat stasiun, pada stasiun 1 dan II sering dikunjungi masyarakat Pulau Tambelan (Tabel 1). Adapun titik koordinant stasiun penelitian di Pulau Bungin Kecamatan Tambelan sebagai berikut: 
Tabel 1. Titik Koordinat Stasiun Penelitian

\begin{tabular}{ccc} 
Stasiun & Latitude & Longitude \\
1 & $1.022064^{\circ}$ & $107.509730^{\circ}$ \\
2 & $1.020674^{\circ}$ & $107.513540^{\circ}$ \\
\hline
\end{tabular}

\subsection{Teknik Pengumpulan Data}

Sumber data terdiri dari data primer dan data sekunder serta meliputi parameter biofisik pantai dan kondisi sosial. Pada tahap penentuan stasiun pengamatan dilakukan berdasarkan hasil observasi awal di lokasi. Titik stasiun ditentukan secara purposive sampling yaitu penentuan titikstasiun secara sengaja berdasarkan keberadaan kondisi pantai dan tingkat aksesibilitas pada Pulau Bungin, Stasiun penelitian dibagi 2 titik yaitu stasiun pengamatan, I meliputi seluruh pantai berpasir bagian barat daya Pulau Bungin, stasiun pengamatan II meliputi seluruh pantai bagian barat laut Pulau Bungin, pemilihan kedua stasiun dilakukan karena stasiun I dan II sering dikunjungi masyarakat Pulau Tambelan serta terdapat pasir putih yang memberikan kenyamanan bagi wisatawan. Pengukuran setiap parameter pada kedua stasiun dilakukan tiga kali pengulangan agar data yang didapatkan lebih akurat (Yulisa et al., 2016). Analisis kesesuaian wisata dilakukan untuk mengetahui kesesuaian kawasan untuk wisata pantai perhitungan indeks kesesuaian wisata berdasarkan Yulianda (2007).

\subsection{Analisis Data}

Analisis kesesuaian wisata dilakukan untuk mengetahui kesesuaian kawasan untuk wisata pantai perhitungan indeks kesesuaian wisata berdasarkan Yulianda (2007). Rumus yang digunakan untuk kesesuaian wisata pantai adalah:

Keterangan :

$$
\mathrm{IKW}=\Sigma \frac{[N i] \times 100 \%}{N \text { maks }}
$$

$\begin{array}{ll}\mathrm{IKW} & =\text { Indeks Kesesuaian Wisata } \\ \mathrm{Ni} & =\text { Nilai total keseluruhan (Bobot X Skor) } \\ \mathrm{Nmaks} & =\text { Nilai maksimum dari suatu kategori wisata }\end{array}$

Daya dukung kawasan adalah jumlah maskimum pengunjung yang secara fisik dapat ditampung oleh kawasan yang disediakan pada waktu tertentu tanpa menimbulkan gangguan pada alam dan manusia (Yulianda et al., 2010): Perhitungan untuk analisis daya dukung kawasan ini, mengacu rumus sebagai berikut:

$$
\mathrm{DDK}=\mathrm{K} \times \frac{\mathrm{Lp} \times \mathrm{Wt}}{\mathrm{Lt} \times \mathrm{Wp}}
$$

\section{Keterangan :}

DDK = Daya dukung kawasan (orang).

$\mathrm{K} \quad=$ Kapasitas ekologi per satuan unit area .

Lp = Luas area yang dapat dimanfaatkan $\left(\mathrm{m}^{2}\right)$.

Lt $\quad=$ Unit area untuk kategori tertentu $\left(\mathrm{m}\right.$ dan $\left.\mathrm{m}^{2}\right)$.

Wt = Waktu yang disediakan oleh kawasan untuk kegiatan wisata dalam 1 hari (jam),

$\mathrm{Wp} \quad$ = Waktu yang dihabiskan oleh pengunjung untuk setiap kegiatan (jam).

\section{HASIL DAN PEMBAHASAN}

\subsection{Potensi Ekologi Pulau Bungin}

\subsubsection{Kedalaman Perairan Pulau Bungin}

Kegiatan wisata pantai khususnya renang sangat penting untuk keselamatan pada saat berenang. Kedalaman perairan dangkal baik untuk dijadikan sebagai objek rekreasi renang karena tidak berbahaya dibandingkan perairan yang dalam. Kedalaman perairan Pantai Bungin dapat dilihat pada Gambar 2. 


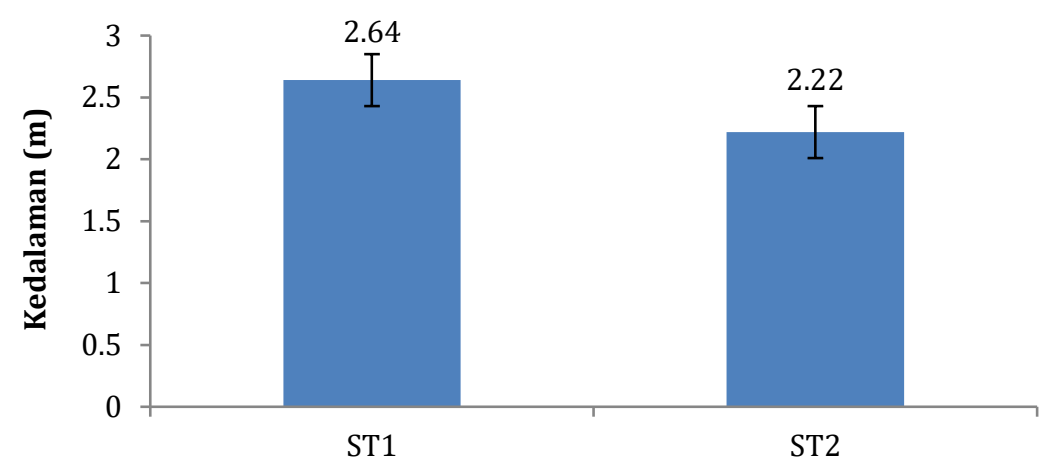

Gambar 2. Nilai Kedalaman Perairan Pulau Bungin

Pengukuran kedalaman perairan Pantai Bungin kedalaman perairan relatif dangkal dan baik untuk dijadikan untuk objek ekowisata pantai kategori rekreasi terutama mandi dan berenang kedalaman yang baik yaitu berkisar 0-3 m. Pantai Bungin memiliki kareteristik yaitu rata-rata kedalaman $2 \mathrm{~m}$ sehingga dapat disimpulkan bahwa Pantai Pulau Bungin sangat sesuai (Sl). sesuai dengan pendapat (Eriawati et al., 2019) yang memberikan batasan nilai kedalaman untuk kesesuaian kedalaman untuk ekowisata pantai kategori cukup sesuai antara 3-6 m.

\subsubsection{Tipe Pantai Pulau Bungin}

Berdasarkan hasil observasi secara visual di lapangan pada masing-masing stasiun pengamatan didapatkan hasil yang disajikan pada Tabel 2.

Tabel 2. Hasil Pengamatan Tipe Pantai Pulau Bungin

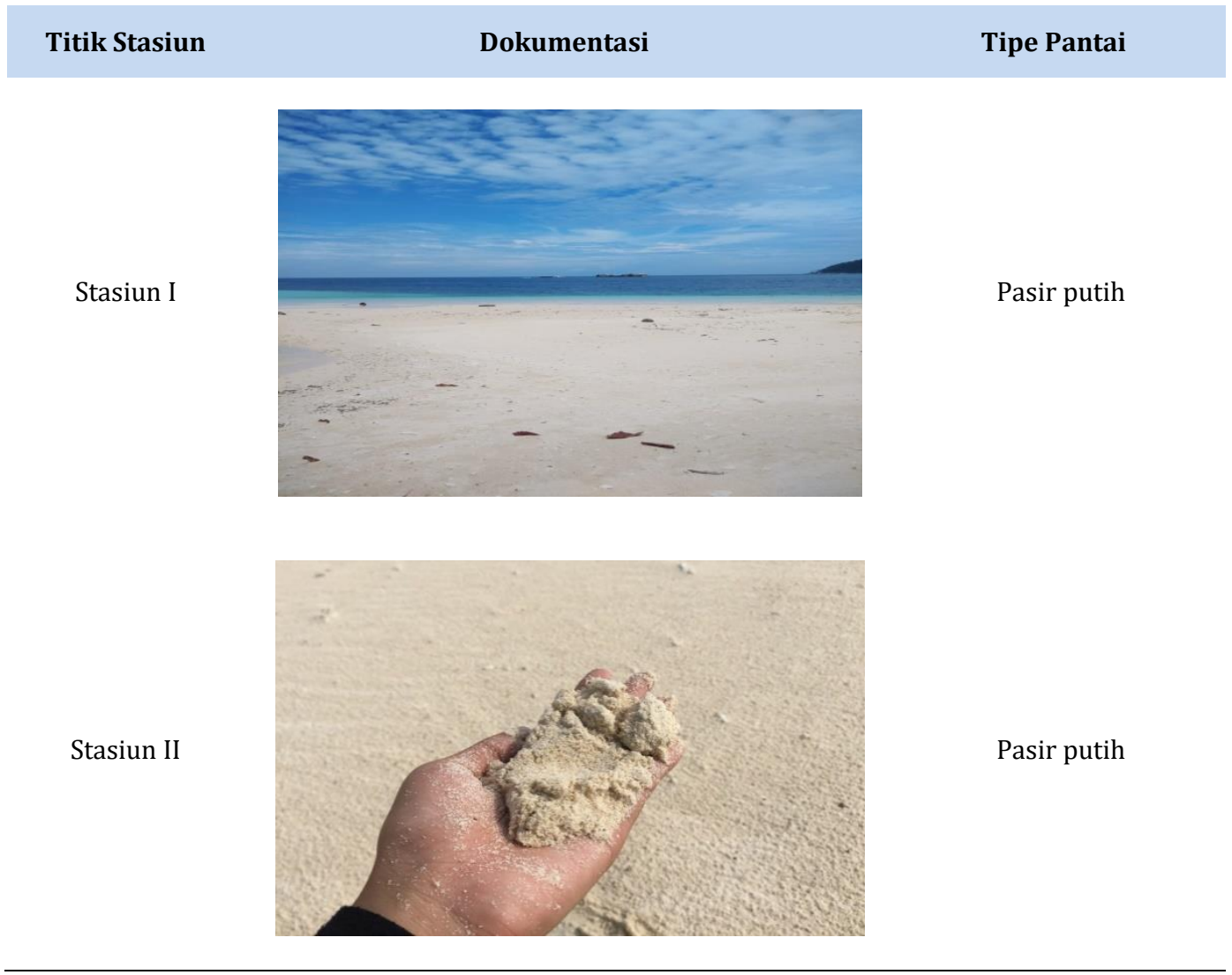

Sumber: Data Primer (2018)

Hasil observasi dan pengamatan secara visual tipe pantai pada masing-masing stasiun di pantai Pulau Bungin merupakan pasir putih. Berdasarkan matriks kesesuaian wisata, stasiun I dan II tergolong dalam kategori Sl (Sangat Sesuai) untuk kegiatan wisata pantai. Pantai yang memiliki tekstur pasir pantai yang halus menjadi salah satu faktor penting dalam berwisata rekreasi pantai jika dibandingkan pantai berbatu dan berkarang, (Chasanah et al.,2017; Mizan et al., 2018). 


\subsubsection{Lebar Pantai Pulau Bungin}

Berdasarkan hasil pengukuran pada masing-masing stasiun pengamatan didapatkan bahwa lebar pantai pada stasiun I yaitu $22.83 \mathrm{~m}$, stasiun II yaitu $27.50 \mathrm{~m}$. Berdasarkan matrik kesesuaian wisata satasiun I termasuk dalam kesesuaian Sl (Sangat Sesuai). Pada stasiun II lebar pantai termasuk dalam kesesuaian Sl (Sangat Sesuai). Nilai dari kesesuaian lebar pantai dapat dilihat pada Tabel 3.

Tabel 3. Hasil Pengukuran Lebar Pantai Pulau Bungin

\begin{tabular}{ccc} 
No & Titik Stasiun & Rata-Rata \\
1 & Stasiun I & 22.83 meter \\
2 & Stasiun II & 27.50 meter \\
\hline & Sumber: Data Primer $(2018)$
\end{tabular}

Berdasarkan hasil pengamatan di lapangan Lebar Pantai Pulau Bungin sangat sesuai untuk dijadikan objek wisata pantai karena Pantai Bungin memiliki pantai yang landai dimana wisatawan yang datang ke Pantai Bungin bisa bermain pasir, bermain ombak di tepi Pantai. Lebar Pantai Bungin >22 menurut pendapat Yulianda (2007) sangat sesuai (S1) jika dijadikan Kawasan Untuk Wisata Pantai Rekreasi.

\subsubsection{Material Dasar Perairan Pulau Bungin}

Pengukuran material dasar perairan dimaksudkan untuk mengetahui substrat dari suatu tempat wisata pantai. Material dasar perairan tersebut diukur menggunakan sieve net dan diolah menggunakan gradistat. Berdasarkan pengamatan visual tentang subsrat dasar perairan pada kedua stasiun perairan Pulau Bungin sesuai dengan matrik kesesuaian di mana substrat dasar berpasir paling ideal untuk menunjang aktivitas wisata pantai.

Jenis substrat pantai Pulau Bungin pada stasiun I didominasi oleh pasir (Slightly Gravelly Sand) sehingga dapat disumpulkan bahwa material dasar perairan Pulau Bungin termasuk dalam kategori pasir dengan nilai rata-rata 98.6\% dan hanya sedikit kerikil dengan nilai rata $1.4 \%$ saja, pada stasiun I material dasar perairan termasuk dalam S1 atau sangat sesuai untuk wisata pantai.

Pada stasiun II jenis material dasar perairan ialah pasir, dengan nilai rata-rata $97.9 \%$, jenis pasir yang ada di perairan Pulau Bungin, stasiun II ialah pasir (Slightly Gravelly Sand). Untuk itu material dasar perairan di stasiun II juga termasuk dalam kategori Sl atau sangat sesuai. Kamah et al. (2013) berpendapat bahwa pantai berpasir merupakan pantai yang didominasi oleh hamparan atau daratan pasir, baik yang berupa pasir hitam, abu-abu atau putih

\subsubsection{Kecepatan Arus Pulau Bungin}

Sukandarrumidi (2009), bahwa pantai yang terlindung dari hembusan angin yang terhalang oleh keberadaan pulau lain yang mempengaruhi arus sesuai untuk mandi dan berenang di laut. Pengukuran kecepatan arus dapat dilihat pada Tabel 4 .

Tabel 4. Hasil Pengukuran Kecepatan Arus Pulau Bungin

\begin{tabular}{ccc} 
No & Titik Stasiun & Nilai Kecepatan Arus \\
1 & Stasiun I & $0.05 \mathrm{~m} / \mathrm{dtk}$ \\
2 & Stasiun II & $0.07 \mathrm{~m} / \mathrm{dtk}$ \\
\hline \multicolumn{3}{c}{ Sumber: Data Primer $(2018)$}
\end{tabular}

Berdasarkan hasil pengukuran kecepatan arus di perairan pantai Pulau Bungin pada saat surut yang disajikan pada pada Tabel 4 menunjukkan pola arus permukaan mempunyai kecepatan berkisar antara 0.05-0.07 m/dtk pada titik sampling I dan II, dimana kecepatan arus tersebut tergolong arus yang lambat dan termasuk kategori Sl atau sangat sesuai untuk aktivitas wisata pantai. Hal ini sesuai dengan pernyataan Yulianda (2007), bahwa kecepatan arus sangat sesuai untuk kegiatan wisata pantai yaitu 0-0,17 m/dtk.

\subsubsection{Kemiringan Pantai Pulau Bungin}

Secara lengkap hasil pengukuran kemiringan pantai disajikan pada Tabel 5.

Tabel 5. Hasil Pengukuran Kemiringan Pantai Pulau Bungin

\begin{tabular}{c|cc} 
No & Titik Stasiun & Nilai Kemiringan \\
1 & Stasiun I & $5.14^{\circ}$ \\
2 & Stasiun II & $8.53^{\circ}$ \\
\hline \multicolumn{3}{c}{ Sumber: Data Primer (2018) }
\end{tabular}

Berdasarkan hasil pengukuran kemiringan pantai pada stasiun I dan II yaitu 5.14ำ dan $8.53^{\circ}$ (Tabel 16). Pada stasiun I dan II termasuk dalam kategori kesesuaian Sl (Sangat Sesuai) dan termasuk kategori pantai datar, Pantai 
datar sampai landai sangat baik untuk kegiatan wisata renang dimana wisatawan dapat melakukan berbagai kegiatan seperti berenang, bermain pasir serta dapat bermain-main dengan ombak di tepinya.

Kemiringan pantai Pulau Bungin pada kedua stasiun pengukuran parameter yaitu $<10^{\circ}$ seperti yang disajikan pada Tabel 5. Berdasarkan hasil pengukuran tersebut dapat disimpulkan kemiringan pantai Pulau Bungin tergolong datar dan termasuk kategori Sl atau sangat sesuai untuk aktivitas wisata pantai dengan kondisi parameter yang sangat baik yaitu skor 3.

\subsubsection{Kecerahan Perairan Pulau Bungin}

Hasil pengukuran kecerahan perairan dapat dilihat pada Tabel 6.

Tabel 6. Hasil Pengukuran Kecerahan Pantai Pulau Bungin

\begin{tabular}{ccc} 
No & Titik Stasiun & Nilai Kecerahan \\
1 & Stasiun I & $100 \%$ \\
2 & Stasiun II & $100 \%$ \\
\hline & Sumber: Data Primer (2018)
\end{tabular}

Berdasarkan hasil pengukuran kecerahan di lapangan kecerahan di perairan Pantai Bungin yaitu $100 \%$. Maka dapat disimpulkan kecerahan perairan di Pantai Bungin sangat ideal untuk Wisata Rekreasi dan Berenang, Begitu juga di Pantai Bungin yang diamati langsung oleh peneliti bahwa dasar Perairan di Pantai Bungin masih tampak dilihat dengan pengamatan visual.

\subsubsection{Jenis Biota Berbahaya Pulau Bungin}

Pengamatan biota berbahaya perlu dilakukan untuk mengetahui keberadaan biota berbahaya yang akan menganggu pengunjung wisata. Pengamatan biota berbahaya dilakukan berdasarkan snorkeling di sekitar stasiun penelitian serta hasil wawancara (Masita, 2013). Adapun biota berbahaya bagi pengunjung wisata diantaranya gastropoda, bulu babi, ubur-ubur. Hasil wawancara dari responden dapat dilihat pada Tabel 7.

Tabel 7. Jenis Biota Berbahaya Pulau Bungin

$\begin{array}{llc}\text { No Jenis Biota Berbahaya } & \text { Nama Lokal } & \text { Nama Ilmiah } \\ 1 & \text { Ubur-ubur } & \begin{array}{c}\text { Jellyfish (Aurelia } \\ \text { aurita) }\end{array} \\ \text { Diadema setosum }\end{array}$

Kondisi ini terkategori sesuai bersyarat (S2) atau cukup sesuai dimana adanya faktor pembatas yang mengurangi kepuasan pengunjung karena dapat membahayakan pengunjung saat beraktivitas di pantai.

\subsubsection{Aksesibilitas Pulau Bungin}

Kondisi aksesibilitas menuju kawasan wisata pantai sangat berperan penting dalam mendukung kegiatan wisata, aksesibilitas dalam berwisata mutlak dibutuhkan oleh pelaku usaha sebagai akses menuju tempat wisata tujuan.Sarana Jalan, telekomunikasi, terminal, jembatan, dan lainnya perlu dianalisis untuk melihat kesiapan suatu daerah pengembangan ekowisata dan disesuaikan dengan lokasi serta kondisi objek wisata yang bersangkutan (Tuwo, 2011). 
Akses jalur laut menuju Pulau Bungin ditempuh menggunakan kapal motor atau pompong yang dapat dilihat pada Gambar 3.

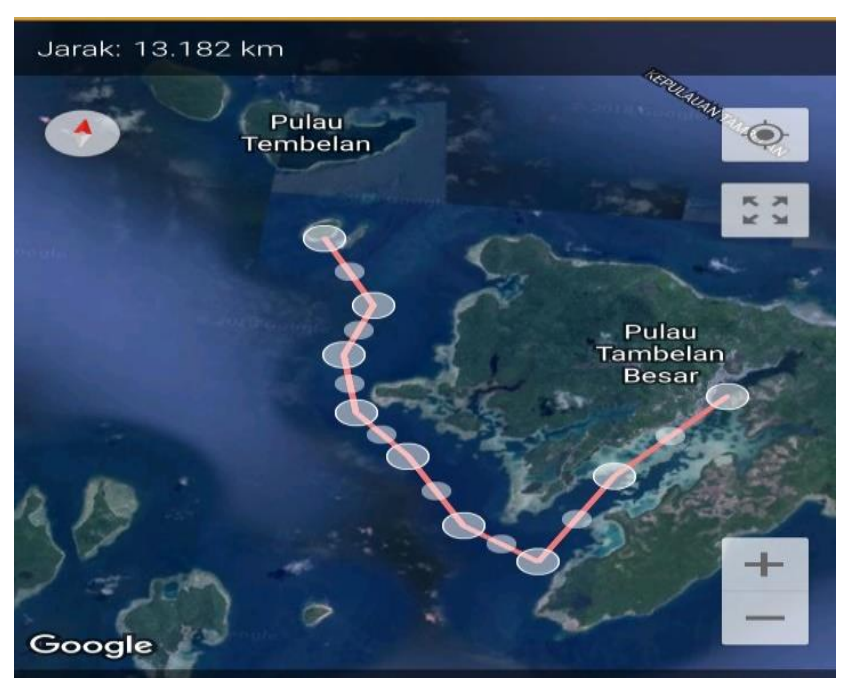

Gambar 3. Aksesibilitas Transportasi Laut ke Pulau Bungin

\subsubsection{Sarana dan Prasarana Pulau Bungin}

Sarana dan prasarana wisata merupakan pelengkap daerah tujuan wisata yang diperlukan untuk melayani kebutuhan wisatawan dalam menikmati perjalanan wisatanya. Sarana dan prasarana dilihat dari 3 ketentuan yaitu akomodasi, tempat makan dan minum serta fasilitas umum, (Fajriah \& Masadun, 2014).

Berdasarkan hasil analisis sarana dan prasarana Pulau Bungin tidak memenuhi 3 ketentuan sebagai pendukung aktivitas wisata pantai yang terkategori $\mathrm{N}$ atau tidak sesuai untuk kegiatan wisata dengan skor 0 yaitu kondisi parameter dengan kualitas buruk. Kondisi seperti ini memiliki faktor pembatas yang dapat mengurangi kepuasan pengunjung dan perlu adanya implikasi pengelolaan demi menunjang aktivitas wisata pantai karena dalam mewujudkan sebuah kawasan wisata yang baik, berbagai sarana dan prasarana wisata yang harus disediakan di daerah tujuan wisata, (Perdana et al., 2016)

\subsubsection{Penutupan Lahan Pantai Pulau Bungin}

Berdasarkan hasil pengamatan penutupan lahan pantai yang telah dilakukan di Pantai Bungin ditemukan beragam jenis tumbuhan pantai (Tabel 8). Pada Stasiun I penutupan lahan pantai berupa lahan terbuka, dan pohon Kelapa termasuk dalam kategori kesesuaian S1 (Sangat Sesuai) dan Stasiun II penutupan pantai berupa lahan terbuka termasuk dalam kategori kesesuaian Sl (Sangat Sesuai).

Tabel 8. Hasil Pengamatan Penutupan Lahan Pantai Pulau Bungin

\begin{tabular}{ccc} 
Titik & Dokumentasi & Keterangan \\
Stasiun & Lahan Terbuka, Kelapa \\
Stasiun I & & \\
Stasiun II & Lahan Terbuka \\
\hline
\end{tabular}

Sumber: Data Primer (2018) 


\subsection{Indeks Kesesuaian Wisata Pantai di Pulau Bungin}

Penentuan nilai (IKW) didasarkan oleh observasi lapangan dan pengukuran yang dilakukan di dua Pantai Pulau Bungin. Hasil analisis indeks kesesuaian wisata pantai di Pulau Bungin Kecamatan Tambelan pada Stasiun I dan Stasiun II dapat dilihat pada Tabel 9 dan Tabel 10.

Tabel 9. Tingkat Kesesuaian Kawasan Wisata Pantai Pulau Bungin Stasiun I

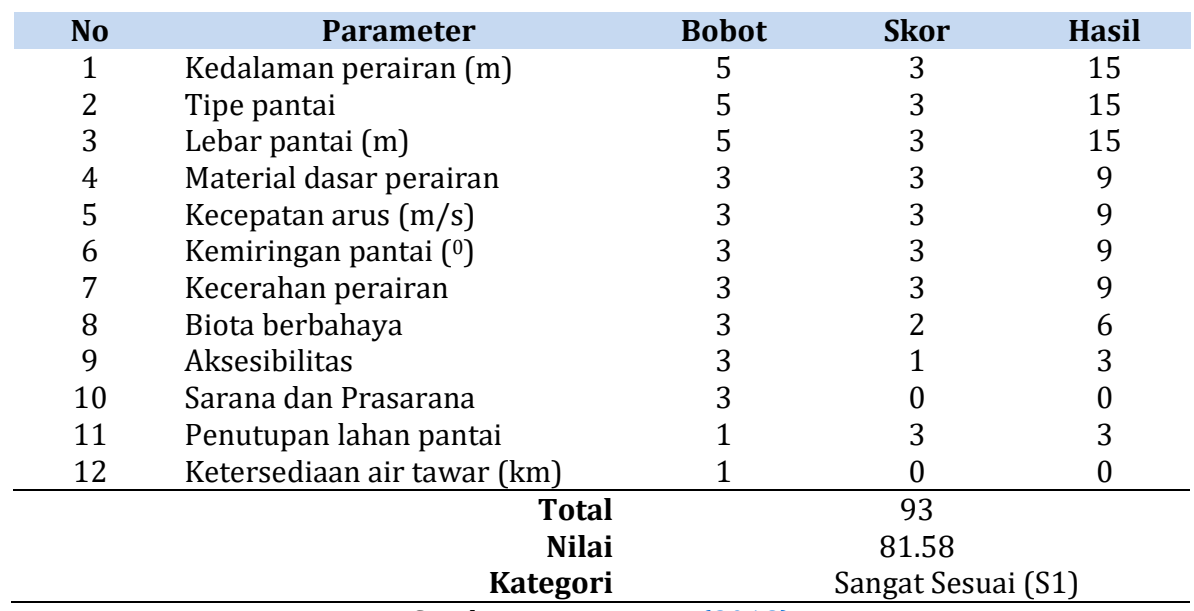

Sumber: Data Primer (2018)

Tabel 10. Matriks Kesesuaian Kawasan Wisata Pantai Pulau Bungin Stasiun II

\begin{tabular}{ccccc} 
No & Parameter & Bobot & Skor & Hasil \\
1 & Kedalaman perairan $(\mathrm{m})$ & 5 & 3 & 15 \\
2 & Tipe pantai & 5 & 3 & 15 \\
3 & Lebar pantai $(\mathrm{m})$ & 5 & 3 & 15 \\
4 & Material dasar perairan & 3 & 3 & 9 \\
5 & Kecepatan arus (m/s) & 3 & 3 & 9 \\
6 & Kemiringan pantai (0) & 3 & 3 & 9 \\
7 & Kecerahan perairan & 3 & 3 & 6 \\
8 & Biota berbahaya & 3 & 2 & 3 \\
9 & Aksesibilitas & 3 & 1 & 3 \\
10 & Sarana dan Prasarana & 3 & 0 & 0 \\
11 & Penutupan lahan pantai & 1 & 3 & 0 \\
12 & Ketersediaan air tawar (km) & 1 & 93 & \\
\hline
\end{tabular}

Sumber: Data Primer (2018)

Kesesuaian kawasan wisata pantai pada stasiun I Pulau Bungin berdasarkan perhitungan Indeks Kesesuaian Wisata (IKW) menunjukan hasil kategori Sangat Sesuai (Sl) dengan nilai IKW sebesar 81,58\%. Tabel 10 menunjukkan bahwa kawasan pantai Pulau Bungin pada stasiun II sangat sesuai (Sl) untuk dijadikan sebagai kawasan wisata pantai.Kondisi ini dilihat dari nilai Indeks Kesesuaian Wisata (IKW) yaitu 81.58\%. Dari kedua stasiun pengamatan di Pulau Bungin, parameter kesesuaian wisata pantai yang memiliki skor paling rendah antara lain aksesibilitas, sarana dan prasarana, sertra ketersediaan air tawar.

\subsection{Daya Dukung Kawasan Pulau Bungin}

Menurut Nugraha et al. (2013) konsep daya dukung ini dikembangkan terutama untuk mencegah kerusakan atau degradasi dari suatu sumberdaya alam dan lingkungan sehingga kelestarian, keberadaan, dan fungsinya dapat tetap terwujud dan pada saat yang bersamaan, masyarakat atau pengguna sumberdaya tersebut akan tetap berada dalam kondisi sejahtera dan atau tidak dirugikan (Intergenerational Welfare).

Hasil perhitungan daya dukung kawasan pantai pulau Bungin pada stasiun I ialah 112 jiwa dengan pemanfaatan luas area $50 \mathrm{~m}^{2}$ orang untuk waktu kunjungan selama 3 jam/orang, dengan lebar pantai $2801.1 \mathrm{~m}^{2}$ dengan aktifitas rekreasi pantai seperti, memancing, berenang.

Daya dukung kawasan pantai pulau Bungin pada stasiun II ialah 138 jiwa dengan pemanfaatan luas area 50 $\mathrm{m}^{2}$ /orang untuk waktu kunjungan selama 3 jam/orang/, pada lebar pantai $3447.4 \mathrm{~m}^{2}$ dengan aktifitas rekreasi pantai seperti berenang, dan lain-lain. 


\section{SIMPULAN}

Potensi ekologis Pulau Bungin dari 12 parameter secara umum sangat sesuai untuk dijadikan wisata pantai, hanya parameter aksesibilitas, sarana dan prasarana, sertra ketersediaan air tawar yang tidak sesuai untuk dijadikan wisata pantai. Indeks kesesuaian kawasan wisata (IKW) Pulau Bungin Stasiun I dan II tergolong sangat sesuai (Sl). Nilai daya dukung kawasan pantai pulau Bungin pada Stasiun I adalah 112 orang selama 3 jam/orang dan Stasiun II ialah 138 orang dengan aktifitas rekreasi pantai, berenang, dan lain-lain.

\section{UCAPAN TERIMA KASIH}

Terimakasih disampaikan kepada Pemerintah Kabupaten Bintan, khususnya Kecamatan Tambelan yang telah memberikan izin turun ke lokasi, serta untuk Dosen pembimbing dan Dosen penguji yang telah berperan penting dalam penyelesaian penelitian ini.

\section{REFERENSI}

BPS Kepulauan Riau. (2014). Badan Pusat Statistik. Tambelan Dalam Angka Tahun 2014. Badan Pusat Statistik Provinsi Kepulauan Riau. Kepulauan Riau.

BPS Kepulauan Riau. (2015). Badan Pusat Statistik. Kepulauan Riau Dalam Angka 2015. Badan Pusat Statistik Provinsi Kepulauan Riau. Kepulauan Riau.

Chasanah, I., Purnomo, P.W., \& Haeruddin. (2017). Analisis Kesesuaian Wisata Pantai Jodo Desa Sidorejo Kecamatan Gringsing Kabupaten Batang. Jurnal Pengelolaan Sumberdaya Alam dan Lingkungan. 7(3): 235-243.

Effendi, H. (2003). Telaah Kualitas Air bagi Pengelolaan Sumberdaya. Kanisus. Jakarta. 257p.

Eriawati, H., Lestari, F., \& Kurniawan, D. (2019). Analisis Kesesuaian Kawasan Wisata Pantai di Pulau Terkulai Kelurahan Senggarang Kota Tanjungpinang. Jurnal Akuatiklestari, 2(2): 38-51. https://doi.org/10.31629/akuatiklestari.v2i2.2364

Karnanda, K., Lestari, F., \& Kurniawan, D. (2019). Analisis Kesesuaian Kawasan Perairan Pulau Bungin untuk Ekowisata Snorkeling di Kecamatan Tambelan Kabupaten Bintan. Jurnal Pengelolaan Perairan. 2(1): 1-10.

Masita, H.K., Femy, M.S., \& Sri, N.H. (2013). Kesesuaian Wisata Pantai Berpasir Pulau Saronde Kecamatan Pondo Kepulauan Pondo. Kabupaten Gorontalo Utara.

Mizan, A., Lestari, F., \& Susiana. (2018). Tingkat Kesesuaian dan Daya Dukung Wisata Pantai di Pulau Penjalin, Kabupaten Kepulauan Anambas. Jurnal Akuatiklestari. 2(1): 1-8. https://doi.org/10.31629/akuatiklestari.v2il.919

Saputra, E., Ulfah, F., \& Kurniawan, D. (2018). Valuasi Ekonomi Ekosistem Terumbu Karang di Perairan Pulau Nyamuk Kecamatan Siantan Timur Kabupaten Kepulauan Anambas Provinsi Kepulauan Riau. Repository UMRAH.

Sukandarrumindi. (2009). Mari Kembali ke Laut: Mengenal Potensi Bahari yang Tak Habis Terkuras (dengan Studi Kasus). Yayasan Pustaka Nusatama. Yogyakarta.

Umar, H. (2012). Metode Floating Object untuk Pengukuran Arus Menyusur Pantai. Jurnal Riset dan Teknologi Kelautan. 10(2): 157-167.

Wanda. I.B.K., \& Pangestuti. E. (2018). Pengaruh Pengembangan Komponen Destinasi Wisata terhadap Kepuasan Pengunjung (Survei pada Pengunjung Situs Trowulan). Jurnal Adnministrasi Bisnis. 55(3): 83-91.

Yulianda, F. (2007). Ekowisata Bahari Sebagai Alternatif Pemanfaatan Sumberdaya Pesisir Berbasis Konsevasi. Makalah seminar Sains Pada Dapertemen Manajemen Sumberdaya Perairan. Fakultas Perikanan Dan Ilmu Kelautan. Insitut Pertanian Bogor (IPB). Bogor.

Yulianda, F., Fahrudin, A., Hutabarat, A.A., Harteti, S., \& Kusharjani, K.S.H. (2010). Pengelolaan Sumberdaya Pesisir dan Laut secara Terpadu. Pusdiklat Kehutanan, Departemen Kehutanan RI-SECEM-Korea International Cooperation Agency. Bogor. 